\title{
Substance abuse in patients admitted voluntarily and involuntarily to acute psychiatric wards: a national cross-sectional study
}

\author{
Anne Opsal ${ }^{1}$, Øistein Kristensen ${ }^{1}$, Torleif Ruud ${ }^{2,3}$, Tor K. Larsen ${ }^{1,4}$, \\ Rolf W. Gråwe ${ }^{5,6}$ and Thomas Clausen ${ }^{1,5}$ \\ 1) Addiction Unit, Sørlandet Hospital, Kristiansand, Norway \\ 2) R\&D Department, Division of Mental Health Services, Akershus University Hospital, Norway \\ 3) Institute of Clinical Medicine, Faculty of Medicine, University of Oslo, Oslo, Norway \\ 4) Regional Centre for Clinical Research in Psychosis, Stavanger University Hospital, Psychiatric Division, Stavanger, Norway \\ 5) Norwegian Centre for Addiction Research (SERAF), Institute of Clinical Medicine, University of Oslo, Oslo, Norway \\ 6) Department of Research and Development, Alcohol and Drug Treatment Health Trust in Central Norway, Norway \\ Correspondence: Anne Opsal, Sørlandet Hospital, Addiction Unit, P.O. Box 416, NO-4604 Kristiansand, Norway \\ E-mail: anne.opsal@sshf.no Telephone:+4738148000 Telefax:+4738097390
}

\begin{abstract}
Background: Substance abuse and mental disorder comorbidity is high among patients admitted to acute psychiatric wards. The aim of the study was to identify this co-occurrence as a reason for involuntary admission and if specific substance use-related diagnoses were associated with such admissions.

Methods: The study was a part of a multicentre, cross-sectional national study carried out during 2005-2006 within a research network of acute mental health services. Seventy-five percent of Norwegian hospitals providing acute in-patient treatment participated. Substance use was measured using the Clinician Rating Scale and the ICD-10 diagnoses F10-19. Diagnostic assessments were performed by the clinicians during hospital stay.

Results: Overall, 33.2\% ( $\mathrm{n}=1,187)$ of the total patient population $(3,506)$ were abusing alcohol or drugs prior to admission according to the Clinician Rating Scale. No difference in the overall prevalence of substance abuserelated diagnoses between the two groups was found. Overall, $310(26 \%)$ of the admissions, 216 voluntarily and 94 involuntarily admitted patients received a double diagnosis. Frequent comorbid combinations among voluntarily admitted patients were; a combination of alcohol and either mood disorder (40\%) or multiple mental disorders (29\%). Among involuntarily admitted patients, a combination of poly drug use and schizophrenia was most frequent (47\%). Substance abusing patients diagnosed with mental and behavioral disorders due to the use of psychoactive stimulant substances had a significantly higher risk of involuntary hospitalization (OR 2.3).

Conclusion: Nearly one third of substance abusing patients are involuntarily admitted to mental hospitals, in particular stimulant drug use was associated with involuntarily admissions.
\end{abstract}

\section{INTRODUCTION}

The prevalence of substance abuse (SA) among patients admitted to acute psychiatric wards varies according to setting and mode of measurement. Prevalence of such comorbidities among inpatients with severe mental illness ranges from $24.4 \%$ to $70.0 \%$ in reports from single wards [1-6]. Comorbid SA typically complicates recovery from mental health disorders and is associated with increased use of health services $[7,8]$.

Involuntary admission and treatment of mentally ill patients are controversial issues in mental health care worldwide [9]. The frequency of involuntary hospitalizations varies between and even within different countries, and is dependent on legislation, clinical experience, resources, traditions, and attitudes [4,5,10-13]. According to the Norwegian Mental Health Care Act [14], compulsory psychiatric mental health care may take place when the patient is suffering from a suspected or established serious mental disorder to prevent severe deterioration of the patient's health status or in cases where there is an obvious threat to the patient's own life or the life of others.

Involuntary admission rates to psychiatric hospitals in Norway are high compared to other European countries [12]. Published involuntary referral rates for 19982000 from other Nordic and European countries range between 6 (in Portugal) and 218 (in Finland) per 100,000 inhabitants/year $[10,15,16]$. In Norway, the respective incidence rates for civil commitment based on "involuntary referrals", "treatment periods", and number of persons involved were 259, 209, and 186 per 100,000 adults/year according to a study conducted by Iversen et al. [12]. Based on the frequent application of coercive mental health care and the context of high rates of comorbid SA and mental illness in Norway $[1,2,4]$, it is important to further investigate the role of substance abuse among patients admitted to acute psychiatric services. Previous studies have focused either on involuntary admissions and treatment in mental hospitals [4,5] or on substance abuse among mentally ill patients $[1,2]$. However, we have not been able to 
find studies that have examined comorbidity and involuntary admissions to hospitals. One of the aims of this study was to investigate if there were specific substance-related diagnoses associated with involuntary admissions.

In order to provide better treatment it is necessary to explore the extent to which the patient's behavior, i.e. drug use prior to admission, predicts the application of coercion in psychiatric wards.

\section{Aims of the study}

1. To investigate if substance abusing patients had a higher risk of involuntary admission to acute psychiatric wards.

2. To investigate whether there could be typical patterns of diagnostic comorbidity of substance abuse and mental disorders among patients abusing psychoactive substances prior to admission to acute psychiatric wards.

3. To investigate if there could be specific substancerelated diagnoses associated with involuntary admissions.

\section{MATERIALS AND METHODS}

\section{Setting}

In Norway the application of coercive mental health care for the mentally ill patients is covered by the Mental Health Care Act [14]. The most common causes for involuntary hospital admission in mental health care are schizophrenia, paranoid psychoses, and acute reactive psychoses [4]. Another act, the Social Services Act $\S 6.2$, covers an option for involuntary admission to the hospital for three months for persons without severe mental illness, but who are primarily addicted to psychoactive substances and whose substance abuse may cause risk to their physical or mental health [17]. In 2009 in Norway, a total of 87 decisions were made for substance abusing persons for involuntary admissions to institutions according to the Social Services Act [18], whereas more than 7,200 patients were admitted involuntarily based on the Psychiatric Healthcare Act [19]. Many of these were patients with substance abuse problems typically treated in psychiatric hospitals, rather than in drug treatment facilities [17].

In 2004 the national health authorities reorganized the funding of alcohol and drug abuse treatment and the responsibility for provision of care was transferred from the counties to the Specialist Healthcare Authorities. Currently, Social Services, together with the Psychiatric Specialist Healthcare Services and the Specialist Substance Abuse Services, share joint responsible for SA patients. Nevertheless, these services often operate independently with limited interaction. Thus, the group of vulnerable substance abuse patients often experience problems when admitted to the Specialist Substance Abuse Services leaving them suffering from lack of treatment addressing their specific needs [18].

\section{Study subjects}

This study was part of the cross-sectional Multicentrestudy of Acute Psychiatry (MAP) in Norway. The data collection was carried out as a national cross-sectional study during 2005 and 2006 within a research network of acute mental health services. Data on patient characteristics and treatment episodes were collected from all patients admitted during a three-month period. The network was organized and coordinated by the research institute SINTEF Health Research in Norway with support from the Norwegian Directorate of Health and Social Affairs [20,21].

The sample originally consisted of 39 wards, which were categorized into three groups: 4 admission wards, 28 acute wards, and 6 subacute wards. One ward was an intermediate term ward and was removed from the sample, resulting in a total of 38 acute wards. This comprised $75 \%$ of Norwegian hospitals providing acute inpatient treatment. The clinics were located in both urban and rural parts of the country and were assumed to cover a representative sample of the Norwegian population [20]. Data from 3,506 admissions to adult acute psychiatric wards were collected. Very few patients may have had more than one admission in the 3-month inclusion period. Thirty-five percent of patients were involuntarily admitted to the hospital [22].

\section{Instrument and measures}

Drug and alcohol use during the six months prior to index hospital admission was assessed by the Clinician Rating Scale [23,24], which measures the consumption of psychoactive substances on a scale from 1 to 5 . The ratings are $1=$ no use, $2=$ use without impairment, $3=$ abuse, $4=$ dependence, and $5=$ dependence with need for institutionalization. The use of psychoactive substances without impairment is defined as "no evidence of persistent or recurrent problems in social functioning, legal status, role functioning, mental status, or physical status, and no evidence of recurrent dangerous use". The patients were subsequently divided into two groups:

1. The non-substance abuse group including patients who scored 1 or 2 on the Clinician Rating Scale (for alcohol and/or drugs).

2. The substance abuse group including patients who scored 3, 4, or 5 on the Clinician Rating Scale (for alcohol and/or drugs).

Demographic, administrative, and clinical information, in addition to one primary and up to two secondary ICD-10 diagnoses [25], were recorded for each patient. Diagnoses were based on "routine clinical assessments", and on structured clinical interviews that measured SA over different time periods. The Clinician Rating Scale measured alcohol and drug use, respectively, during the six months prior to admission, whereas ICD-10, F10-19 diagnoses represent current substance use disorders as judged by the clinician during the hospital stay. The focus of this study was on 
Table 1. Patient demographics and premorbid functioning of voluntarily and involuntarily hospitalized patients with substance abuse according to Clinician Rating Scale.

\begin{tabular}{lccr}
\hline & $\begin{array}{c}\text { Voluntary } \\
\text { admission }\end{array}$ & $\begin{array}{c}\text { Involuntary } \\
\text { admission }\end{array}$ & $P$-value \\
\hline$N=1187$ (\%) & $826(70)$ & $361(30)$ & \\
Mean age (SD) & $36.7(12)$ & $34.4(11.9)$ & 0.002 \\
Male (\%) & 63 & 64 & 0.705 \\
Living with partner (\%) & 18 & 15 & 0.140 \\
Housing & & & \\
$\quad$ Rented or owned (\%) & 68 & 57 & $<0.001$ \\
$\quad$ Homeless or hospice (\%) & 11 & 11 & 0.931 \\
Employed (\%) & 10.2 & 8.6 & 0.459 \\
Education beyond primary school (\%) & 44 & 38 & 0.028 \\
Mean number of days since last discharge (SD) & $110(149)$ & $91(147)$ & 0.105 \\
GAF symptoms at admission (mean/SD)* & $39.2(11.3)$ & $30.7(11.8)$ & $<0.000$ \\
GAF social at admission (mean/SD)* & $38.9(9.8)$ & $33.6(10.5)$ & $<0.000$ \\
Suicide risk at admission & & & \\
$\quad$ Suicidal ideation or plans (\%) & 60.1 & 27.7 & $<0.000$ \\
$\quad$ No suicidal self-injurious behaviors (\%) & 9.0 & 5.5 & 0.058 \\
$\quad$ Attempted suicide (\%) & 4.1 & 6.4 & 0.129 \\
$\quad$ No suicide risk (\%) & 24.8 & 50.7 & $<0.000$ \\
Suspect intoxicated on admission** (\%) & 48 & 57 & 0.006 \\
Positive alcohol test on admission (\%) & 13 & 9 & 0.059 \\
Positive drug test on admission (\%) & 12 & 20 & 0.001 \\
Police assisted admittance (\%) & 18 & 62 & $<0.001$ \\
\hline * Global Assessment of Social Functioning, scale from 0 to 100 with lower ratings for more severe problems \\
** As judged by clinicians
\end{tabular}

patients who reported drug use with impact/abuse pattern before admission to acute psychiatric wards. We were therefore notably interested in patients scoring 3 or higher on the Clinician Rating Scale; these patients formed the study sample and the basis for further analysis. Patients were tested for substance use by laboratory drug tests upon hospital admission.

The Global Assessment of Functioning Scale (GAF) was used to rate social, occupational, and psychological functioning. The latter scores were split into symptom scores (GAFs) and function scores (GAFf) [26]. No reliability tests were carried out. All clinicians had experience in rating GAF as a routine measure required in the mental health services.

\section{Analysis and statistical methods}

Continuous data are presented as means with standard deviations (SD) and analyzed using Student's $t$-test when normal distributed. Multiple logistic regression analysis was performed to investigate whether specific substance-related diagnoses predicted involuntary admission (dependent variable). Results are presented with $95 \%$ confidence intervals. Continuous variables were checked for correlation with Spearman's rho; none of the included continuous variables had a correlation $>0.7$. Significance level was set at $P<0.05$. Analyses were performed using SPSS 16.0 software (SPSS Inc., Chicago, IL, USA).

\section{Ethics and informed consent}

The Regional Committee for Medical and Health Research Ethics and the Data Inspectorate, Oslo, Norway
(REK: 211-04049 NSD: 11074) approved the study. The Norwegian Directorate of Health and Social Affairs provided permission to collect information from health services. The Regional Committee for Medical and Health Research Ethics approved that data was collected without asking for consent, as it was considered ethically important also to include those that were involuntarily admitted and would be most likely to not give consent.

\section{RESUlTS}

According to the Clinician Rating Scale, 1,187 of the 3,506 admissions (33.2\% of all admissions) were patients abusing psychoactive substances prior to admission. We found that $826(70 \%)$ of the admissions were voluntarily admitted SA patients and 361 (30\%) were involuntarily admitted SA patients (Table 1).

Two-thirds of both voluntarily and involuntarily admitted SA patients were males, mean age 36 years and 34 years, respectively. Involuntarily admitted patients had more severe problems as measured by GAFs and GAFf scores. Significantly more voluntarily admitted patients than involuntarily admitted patients had suicidal ideation or plans (Table 1). Sixty-two percent of involuntary admissions and $18 \%$ of the voluntary admissions required police assistance. Suspected intoxication rates at admission were higher among involuntarily admitted patients, in particular positive drug tests were found in up to one-fifth of those patients.

At discharge, 290 (35\%) of the voluntarily and 131 $(36 \%)$ of the involuntarily admitted SA patients were 
Table 2. Diagnosis according to ICD-10 of voluntarily and involuntarily hospitalized patients.

\begin{tabular}{lcccr}
\hline & Total & $\begin{array}{c}\text { Voluntary } \\
\text { admission (\%) }\end{array}$ & $\begin{array}{c}\text { Involuntary } \\
\text { admission (\%) }\end{array}$ & $P$-value \\
\hline Diagnosis (primary) & & & & \\
F 10-19 Substance use disorders & $421(35.5)$ & $290(35.1)$ & $131(36.3)$ & 0.696 \\
F 20-29 Schizophrenia disorders & $201(18.7)$ & $88(11.8)$ & $113(34.5)$ & $<0.001$ \\
F 30-39 Mood disorders & $232(21.6)$ & $187(25.1)$ & $45(13.7)$ & $<0.001$ \\
F 40-49 Neurotic disorder & $94(8.8)$ & $84(11.3)$ & $10(3.0)$ & $<0.001$ \\
F 60-69 Personality disorders & $89(8.3)$ & $65(8.7)$ & $24(7.3)$ & 0.462 \\
Substance use diagnosis & & & & \\
(F10.) Alcohol & $197(16.6)$ & $153(18.5)$ & $44(12.2)$ & 0.007 \\
(F11.) Opioids & $20(1.7)$ & $13(1.6)$ & $7(1.9)$ & 0.653 \\
(F12.) Cannabinoids & $22(1.9)$ & $14(1.7)$ & $8(2.2)$ & 0.540 \\
(F13.) Sedatives or hypnotics & $22(1.9)$ & $17(2.1)$ & $5(1.4)$ & 0.429 \\
(F14.) Cocaine & $1(0.1)$ & $1(0.1)$ & $0(0)$ & 0.508 \\
(F15.) Other stimulants & $49(4.1)$ & $24(2.9)$ & $25(6.9)$ & 0.001 \\
(F16.) Hallucinogens & $0(0)$ & $0(0)$ & $0(0)$ & \\
(F18.) Volatile solvents & $1(0.1)$ & $1(0.1)$ & $0(0)$ & 0.508 \\
(F19.) Poly drug & $324(27.3)$ & $213(25.8)$ & $111(30.7)$ & 0.078 \\
No substance diagnosis & $551(46.4)$ & $390(47.2)$ & $161(44.6)$ & 0.442 \\
\hline Total & $1187(100)$ & $826(100)$ & $361(100)$ & \\
\hline
\end{tabular}

Table 3. Patterns of comorbid mental disorders and substance abuse disorders; ICD-10 diagnosis.

\begin{tabular}{llccccc}
\hline & & F10 & F15 & F19 & & \\
& Admission & Alcohol (\%) & Stimulant (\%) & Poly drug (\%) & Other* (\%) & Total (\%) \\
\hline F20-F29 Schizophrenia disorders & Voluntary & $6(8)$ & $5(39)$ & $26(28)$ & $2(6)$ & $39(18)$ \\
& Involuntary & $6(22)$ & $2(40)$ & $22(47)$ & $9(60)$ & $39(42)$ \\
\hline F30-F39 Mood disorders & Voluntary & $30(40)$ & $2(15)$ & $23(25)$ & $15(43)$ & $70(32)$ \\
& Involuntary & $7(26)$ & $1(20)$ & $4(9)$ & $4(27)$ & $17(18)$ \\
\hline F40-F48 Neurotic disorders & Voluntary & $12(16)$ & 0 & $8(9)$ & $4(11)$ & $24(11)$ \\
& Involuntary & $2(7)$ & 0 & $4(9)$ & 0 & $6(6)$ \\
\hline F60-F69 Personality disorders & Voluntary & $1(1)$ & $2(15)$ & $16(17)$ & $6(17)$ & $25(12)$ \\
& Involuntary & $3(11)$ & $1(20)$ & $10(21)$ & $1(7)$ & $16(17)$ \\
\hline Multiple mental disorders & Voluntary & $22(29)$ & $2(15)$ & $13(14)$ & $8(23)$ & $45(21)$ \\
& Involuntary & $8(30)$ & $1(20)$ & $6(13)$ & $1(7)$ & $16(17)$ \\
\hline Other mental disorders & Voluntary & $4(5)$ & $2(15)$ & $7(8)$ & 0 & $13(6)$ \\
& Involuntary & $1(4)$ & 0 & $1(2)$ & 0 & $2(2)$ \\
\hline Total & Voluntary & $75(100)$ & $13(100)$ & $93(100)$ & $35(100)$ & $216(100)$ \\
& Involuntary & $27(100)$ & $5(100)$ & $47(100)$ & $15(100)$ & $94(100)$ \\
\hline
\end{tabular}

* Use of one of: F11. opioids, F12. cannabinoids, F13. sedatives, F16. hallucinogens

given a primary substance abuse diagnosis according to ICD-10 F10-F19 (Table 2). Of the primary mental diagnoses, mood disorders (F30-39) and neurotic disorders (F40-49) were significantly more frequently diagnosed among patients admitted voluntarily. Schizophrenia spectrum disorders (F20-29) were significantly more common among the involuntarily admitted patients. Although no difference in the overall prevalence of substance abuse-related diagnoses between the two groups was found, there were differences in the specific patterns of drug abuse. Among voluntarily admitted patients, alcohol-related diagnoses were significantly more common, whereas stimulant drugs were significantly more common among involuntarily admitted patients. A tendency towards more polydrug use was observed in patients admitted involuntarily.

Overall, 310 of the SA admissions (216 voluntary and 94 involuntary admissions) received a double diagnosis (Table 3). Some typical comorbid patterns of drug use and mental disorders were found. Alcohol use or poly drug use were most frequent. Among the voluntarily admitted patients, a combination of alcohol and either mood disorder (40\%), multiple mental disorders (29\%), or neurotic disorder (16\%) were more frequent. Among involuntarily admitted patients, a combination of poly drug use and schizophrenia was most frequent $(47 \%)$.

Multiple logistic regression analysis was used to investigate whether being involuntarily hospitalized in acute psychiatric wards was associated with any spe- 
Table 4. Drug diagnosis (ICD-10) patterns and associations with involuntary hospitalization in acute psychiatric wards. Bivariate and multivariate analyses.

\begin{tabular}{lcccc}
\hline & $\begin{array}{c}\text { Bivariate analysis } \\
\text { unadjusted OR }(95 \% \mathrm{CI})\end{array}$ & $P$-value & $\begin{array}{c}\text { Multivariate analysis } \\
\text { adjusted OR }(95 \% \mathrm{CI})\end{array}$ & $P$-value \\
\hline Male gender & $0.943(0.729-1.221)$ & 0.657 & $0.939(0.722-1.223)$ & 0.642 \\
Age & $0.984(0.973-0.994)$ & 0.002 & $0.989(0.977-1.000)$ & 0.046 \\
$\begin{array}{l}\text { Substance use Diagnosis } \\
\quad \text { No abuse diagnosis }\end{array}$ & reference & & & \\
$\quad$ Alcohol & $0.700(0.478-1.026)$ & 0.068 & $0.751(0.507-1.111)$ & 0.152 \\
$\quad$ Stimulant & $2.536(1.407-4.573)$ & 0.002 & $2.278(1.266-4.099)$ & 0.006 \\
$\quad$ Multiple drugs & $1.269(0.946-1.702)$ & 0.112 & $1.181(0.873-1.598)$ & 0.281 \\
$\quad$ Other & $1.107(0.632-1.937)$ & 0.722 & $1.062(0.607-1.859)$ & 0.833 \\
\hline
\end{tabular}

cific drug use patterns. The use of stimulants was significantly associated with involuntary admission (OR $2.3,95 \%$ CI 1.266-4.099, $P=0.006$ ) (Table 4).

\section{DISCUSSION}

One-third $(33.2 \%)$ of the total hospital admissions $(n=3,506)$ were patients abusing psychoactive substances prior to admission to acute psychiatric wards according to the Clinician Rating Scale. Of these, 70\% were voluntarily admitted and $30 \%$ involuntarily admitted. No difference in the overall prevalence of substance abuse-related diagnoses between the two groups was found. Among voluntarily admitted SA patients, alcohol-related diagnoses were significantly more common. A tendency towards more polydrug use was observed in patients admitted involuntarily. SA patients diagnosed with mental disorders due to stimulant use had a significantly higher risk for involuntary hospitalization (OR 2.3).

\section{Prevalence and characteristics}

Using the Clinician Rating Scale revealed a prevalence of substance abuse among patients admitted to acute psychiatric wards of $33.2 \%$, which is concordant with similar previous studies. In these studies using the same Clinical Rating Scale as a screening tool on smaller and more selected populations, the reported prevalence varies between $24 \%$ and $69 \%$ [8,27-29]. Studies reporting prevalence of substance use based on self-report tended to underestimate the prevalence compared with studies based on laboratory or on-site drug analyses [30].

Involuntarily admitted patients tested positive significantly more often for substances on drug tests performed at hospital admission. They were more often suspected to be intoxicated. Police assisted admissions were more frequently required (Table 1). However, it is noteworthy that as many as $18 \%$ of the voluntary admissions also required police assistance. Several studies suggest that the patients' experience of being coerced during the admission process to mental hospitals do not necessarily correspond with their legal status [31, 32]. Rather, perceived coercion appears to be associated with a feeling that their views were not taken into consideration in the admission process. In a study by Iversen et al. $32 \%$ of voluntarily admitted patients perceived high levels of coercion in respective of legal status at admission.

\section{Diagnoses and diagnostic comorbidity}

Different modes of substance use detection often result in different prevalence estimates. Applying the Clinicians Rating Scale revealed more substance abusers than that diagnosed by clinicians according to ICD-10 coding. According to the Clinicians Rating Scale, 1,187 of the admissions were patients abusing psychoactive substances. However, only $53 \%$ of these received a substance abuse diagnosis according to ICD-10.

Some typical patterns of diagnostic comorbidity of SA and mental disorders among patients abusing psychoactive substances prior to admission were found. Alcohol and polydrug use were the two most frequently observed patterns. Among patients admitted voluntarily, a combination of alcohol and either mood disorders, multiple mental disorders, or neurotic disorders were common, whereas a combination of polydrug use and schizophrenia was most frequent among involuntarily admitted patients. This is in agreement with the study of Mueser et al. who reported that $53 \%$ of all the involuntarily hospitalized psychiatric patients (SA and non-SA patients) suffered from schizophrenia or schizoaffective disorders, and alcohol was the most commonly abused substance [24].

SA patients diagnosed with mental and behavioral disorders due to psychoactive stimulant use had a significant higher risk for involuntary hospitalization (OR 2.3). This could be due to stimulant-induced psychosis or it may reflect acting-out behavior among stimulantusing patients. Most commonly, stimulant psychosis occurs in drug abusers who take large stimulant doses [33-35]. In nearly every case, the symptoms of amphetamine-induced psychosis (as well as stimulant psychosis in general) will stop within 7-10 days of discontinuing the drug. However, some individuals with long-term or "heavy" use may continue experiencing intermittent psychotic episodes (hallucination, delusions, and/or paranoia) on an ongoing basis during the 
first year of abstinence [36]. It is clinically challenging to differentiate between a drug-induced psychosis and other forms of psychosis during the initial phase.

Stimulants seem to predict involuntary admission in our study. Besides stimulant-induced psychosis, stimulants also often produce an acting-out behaviour and these patients may be agitated, aggressive, hallucinating, demonstrate suicidal behaviour, and require extensive resources when admitted to the hospital [37, 38]. The aggressive behavior rather than the degree of severity of the psychiatric disorder could determinate if admission to hospital becomes voluntary or involuntary. It is of concern if the Mental Health Act designed to provide health care for psychotic patients is regularly used towards non-psychotic but aggressive patients intoxicated by stimulant drugs.

There are some methodological considerations to recognize when interpreting results from this study. First, the cross-sectional study design can only provide associations, not causation. Second, the diagnoses used in this study are clinical diagnoses and not necessarily based on any standardized, structured interviews. Nevertheless, this study has a relatively large sample size, is nationally representative, and may have the power to detect important associations of clinical significance. The large data collection represents the diagnostic reality in a large number of clinical settings in Norway, and not only in a strictly controlled experiment.

This study indicates that more than half $(53 \%)$ of patients abusing substances prior to admission to acute psychiatric wards, addiction treatment alone or in combination with treatment for mental disorders may be more appropriate than mental disorder treatment alone. This and other studies have shown that SA and mental disorders are co-occurring and comorbidity renders treatment more difficult, leading to greater use of health services [8,39]. Therefore, clinical routines to better identify SA among patients receiving mental healthcare should be given higher priority in order to provide optimal treatment, as many of the patients likely would benefit from additional treatment in specialist substance abuse services.

\section{ACKNOWLEDGMENT}

We are thankful to the Norwegian Research Network on Coercion in Mental Health Care and the Norwegian Ministry of Health and Social Affairs for the financial support.

\section{REFERENCES}

1. Flovig JC, Vaaler AE, Morken G. Substance use at admission to an acute psychiatric department. Nord $J$ Psychiatry 2009; 63 (2): 113-119.

2. Helseth V, Lykke-Enger T, Johnsen J, Waal H. Substance use disorders among psychotic patients admitted to inpatient psychiatric care. Nord J Psychiatry 2009; 63 (1): 72-77.

3. Brems C, Johnson ME, Wells RS, Burns R, Kletti N. Rates and sequelae of the coexistence of substance use and other psychiatric disorders. Int J Circumpolar Health 2002; 61 (3): 224-244.

4. Torrissen T. [Involuntary admissions to an acute psychiatric ward]. Tidsskr Nor Laegeforen 2007; 127 (16): 2086-2089.

5. Riecher-Rossler A, Rossler W. Compulsory admission of psychiatric patients - an international comparison. Acta Psychiatr Scand 1993; 87 (4): 231-236.

6. Hodgins S, Larm P, Molero-Samuleson Y, Tengstrom A, Larsson A. Multiple adverse outcomes over 30 years following adolescent substance misuse treatment. Acta Psychiatr Scand 2009; 119 (6): 484-493.

7. Kallert TW. Coercion in psychiatry. Curr Opin Psychiatry 2008; 21 (5): 485-489.

8. Opsal A, Clausen T, Kristensen O, Elvik I, Joa I, Larsen TK. Involuntary hospitalization of first-episode psychosis with substance abuse during a 2-year follow-up. Acta Psychiatr Scand 2011; 124 (3): 198-204.

9. Salize HJ, Dressing H. Coercion, involuntary treatment and quality of mental health care: is there any link? Curr Opin Psychiatry 2005; 18 (5): 576-584.

10. Salize HJ, Dressing H. Epidemiology of involuntary placement of mentally ill people across the European Union. Br J Psychiatry 2004; 184: 163-168.

11. Katsakou C, Priebe S. Outcomes of involuntary hospital admission - a review. Acta Psychiatr Scand 2006; 114 (4): 232-241.

12. Iversen KI, Hoyer G, Sexton HC. Rates for civil commitment to psychiatric hospitals in Norway. Are registry data accurate? Nord J Psychiatry 2009; 63 (4): 301-307.

13. Dressing H, Salize HJ. Compulsory admission of mentally ill patients in European Union Member States. Soc Psychiatry Psychiatr Epidemiol 2004; 39 (10): 797-803.

14. Psykisk helsevernloven (1999). Oslo: Cappelen akademisk forlag, 2009.

15. Poulsen HD, Olsen CE. [Use and registration of coercion in psychiatry in the new millennium]. Ugeskr Laeger 2002; 164 (40): 4664-4667.

16. Kjellin L, Ostman O, Ostman M. Compulsory psychiatric care in Sweden: development 1979-2002 and area variation. Int J Law Psychiatry 2008; 31 (1): 51-59. 
17. Lov om sosiale tjenester mv. Lovdata, 1991.

18. Lundeberg IR, Mjåland K, Nilssen E, Søvig KH, Ravneberg BL. Tvang overfor rusmiddelavhengige. Evaluering av Lov om sosiale tjenester $\S \S 6-2,6-2 \mathrm{a}$ og 6-3 [Compulsory intervention towards substance and alcohol abusers. Evaluation of the Social Service Act $\S \S 6-2,6-2 \mathrm{a}$ and 6-3]. Bergen: Uni Rokkansenteret, Uni Research Bergen, 2010.

19. Ragnhild B, Bernhard PP, Vaarinn H. Bruk av tvang i psykisk helsevern for voksne 2009. Oslo: Helsedirektoratet, 2010.

20. Kroken RA, Johnsen E, Ruud T, Wentzel-Larsen T, Jorgensen HA. Treatment of schizophrenia with antipsychotics in Norwegian emergency wards, a cross-sectional national study. BMC Psychiatry 2009; 9: 24.

21. Ruud T, Gråwe RW, Hatling T. Acute Psychiatric Treatment in Norway - results from a multicenter study (In Norwegian). Sintef Helse, Trondheim, 2006.

22. Husum TL, Bjornegaar JH, Finset A, Torleif R. A cross-sectional prospective study of seclusion, restraint and involuntary medication in acute psychiatric wards: patient, staff and ward characteristics. BMC Health Serv Res 2010; 10: 89.

23. Drake RE, Osher FC, Noordsy DL, Hurlbut SC, Teague GB, Beaudett MS. Diagnosis of alcohol use disorders in schizophrenia. Schizophr Bull 1990; 16 (1): 57-67.

24. Mueser KT, Nordsy DL, Drake RE, Fox L. Integrated Treatment for Dual Disorders. New York: Guildford Press, 2003.

25. Janca A, Ustun TB, Early TS, Sartorius N. The ICD-10 symptom checklist: a companion to the ICD-10 classification of mental and behavioural disorders. Soc Psychiatry Psychiatr Epidemiol 1993; 28 (5): 239-242.

26. Goldman HH, Skodol AE, Lave TR. Revising axis V for DSM-IV: a review of measures of social functioning. Am J Psychiatry 1992; 149 (9): 1148-1156.

27. Larsen TK, Melle I, Auestad B, Friis S, Haahr U, Johannessen JO, et al. Substance abuse in first-episode nonaffective psychosis. Schizophr Res 2006; 88 (1-3): 55-62.

28. Opjordsmoen S, Friis S, Melle I, Haahr U, Johannessen J, Larsen T, et al. A 2-year follow-up of involuntary admission's influence upon adherence and outcome in first-episode psychosis. Acta Psychiatr Scand 2010; 121 (5): 371-376.

29. Mueser KT, Yarnold PR, Rosenberg SD, Swett C, Jr., Miles KM, Hill D. Substance use disorder in hospitalized severely mentally ill psychiatric patients: prevalence, correlates, and subgroups. Schizophr Bull $2000 ; 26$ (1): 179-192.

30. Mordal J, Holm B, Morland J, Bramness JG. Recent substance intake among patients admitted to acute psychiatric wards: physician's assessment and on-site urine testing compared with comprehensive laboratory analyses. J Clin Psychopharmacol 2010; 30 (4): 455-459.

31. Wild TC, Roberts AB, Cooper EL. Compulsory substance abuse treatment: an overview of recent findings and issues. Eur Addict Res 2002; 8 (2): 84-93.

32. Iversen KI, Hoyer G, Sexton H, Gronli OK. Perceived coercion among patients admitted to acute wards in Norway. Nord J Psychiatry 2002; 56 (6): 433-439.

33. Curran C, Byrappa N, McBride A. Stimulant psychosis: systematic review. Br J Psychiatry; 185: 196-204.

34. Sara G, Burgess P, Malhi G, Whiteford H. Amphetamine availability and admissions for psychosis in New South Wales, 2001-2009. Aust N Z J Psychiatry 2011; 45 (4): 317-324.

35. Smith MJ, Thirthalli J, Abdallah AB, Murray RM, Cottler LB. Prevalence of psychotic symptoms in substance users: a comparison across substances. Compr Psychiatry 2009; 50 (3): 245-250.

36. Zorick TS, Rad D, Rim C, Tsuang J. An overview of methamphetamine-induced psychotic syndromes. Addict Disord Their Treat 2008; 7 (3): 143-156.

37. Gray SD, Fatovich DM, McCoubrie DL, Daly FF. Amphetamine-related presentations to an inner-city tertiary emergency department: a prospective evaluation. Med J Aust 2007; 186 (7): 336-339.

38. Derlet RW, Rice P, Horowitz BZ, Lord RV. Amphetamine toxicity: experience with 127 cases. J Emerg Med 1989; 7 (2): 157-161.

39. Wallace C, Mullen PE, Burgess P. Criminal offending in schizophrenia over a 25-year period marked by deinstitutionalization and increasing prevalence of comorbid substance use disorders. Am J Psychiatry 2004; 161 (4): 716-727. 